\title{
Hydrogen-Transfer Alternating Copolymerization of $P$-Ethenyl- $N$-n-propylphosphonamidic Acid Ethyl Ester with Cyclic Phosphonites Involving Oxidation-Reduction Process
}

\author{
Shiro Kobayashi, * Jun-ichi KadoKawa, Hiroshi Uyama, \\ and Shin-ichiro SHODA \\ Department of Molecular Chemistry and Engineering, Faculty of Engineering, \\ Tohoku University, Aoba, Sendai 980, Japan
}

(Received January 25, 1991)

\begin{abstract}
The present paper describes the alternating copolymerization of $P$-ethenyl- $N$ $n$-propylphosphonamidic acid ethyl ester (1) with cyclic phosphonites (2). The copolymerization took place without added catalyst to produce $1: 1$ alternating copolymer 3 . During the copolymerization the oxidation-reduction reaction of monomers occurred. Monomer $\mathbf{1}$ behaved as an oxidant monomer $\left(M_{\mathrm{ox}}\right)$ whereas 2 acted as a reductant monomer $\left(M_{\mathrm{red}}\right)$. The structure and composition of copolymers were determined by ${ }^{1} \mathrm{H}$ and ${ }^{31} \mathrm{P}$ NMR spectra as well as the hydrolysis experiments. The copolymerization is reasonably explained by a mechanism of propagation via zwitterion intermediates. The apparent monomer reactivity ratios determined in benzonitrile at $130^{\circ} \mathrm{C}$ were $r_{1}=0.00$ and $r_{2 \text { (six-membered) }}=0.34$.

KEY WORDS Oxidation-Reduction Alternating Copolymerization / PEthenyl- $N$ - $n$-propylphosphonamidic Acid Ethyl Ester / Cyclic Phosphonites / Oxidant Monomer / Reductant Monomer / Hydrogen-Transfer Process /
\end{abstract}

In a series of studies on alternating copolymerization involving zwitterion intermediates, ${ }^{1}$ we have found various hydrogentransfer copolymerization reactions between 2-phenyl-1,3,2-dioxaphospholane (2a) and vinyl monomers having an acidic hydrogen such as acrylic acid, ${ }^{2}$ acrylamide, ${ }^{2}$ and ethylenesulfonamide. ${ }^{3}$ The copolymerizations occur spontaneously without any added catalyst involving a hydrogen-transfer process to produce $1: 1$ sequence-regulated alternating copolymers. Phosphorus atom in monomer $\mathbf{2 a}$ is trivalent, whereas that is changed to pentavalent in the product copolymer. Thus, an oxidation of phosphorus atom takes place during the copolymerization. Concurrently, the vinyl monomer is reduced.Therefore, the copolymerization is termed as "oxidation-reduction copolymerization". ${ }^{4,5} \mathbf{2 a}$ behaves as a reductant monomer $\left(M_{\text {red }}\right)$ and vinyl monomers behave as oxidant monomers $\left(M_{\mathrm{ox}}\right)$ during the copolymerization.

Very recently we have found an alternating copolymerization of vinylphosphonic acid monoethyl ester with $\mathbf{2 a}{ }^{4}$ in which vinylphosphonic acid monoethyl ester behaved as an oxidant monomer. This paper reports a new hydrogen-transfer alternating copolymerization of $P$-ethenyl- $N$ - $n$-propylphosphonamidic acid ethyl ester (1), $N$ - $n$-propylamide derivative of vinylphosphonic acid monoethyl ester, with three monomers of five, six, and sevenmembered cyclic phosphonites (2). This polymerization involves the reduction of monomer 1 and the oxidation of monomer 2. 


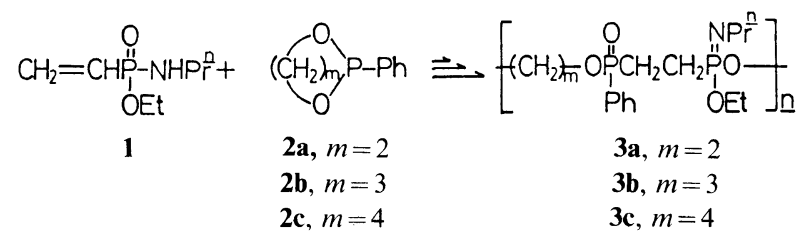

\section{EXPERIMENTAL}

\section{Materials}

Solvents, acetonitrile, benzonitrile, dimethylformamide (DMF) and diethyl ether were purified in a usual manner under argon. Monomers $\mathbf{2 a}-\mathbf{c}$ were prepared according to the literatures. ${ }^{6,7}$

\section{Preparation of P-Ethenyl-N-n-propylphospho- namidic Acid Ethyl Ester 1}

To phosphorus pentachloride $(10.5 \mathrm{~g}, 0.05$ mol) was added vinylphosphonic acid diethyl ester $(8.2 \mathrm{~g}, 0.05 \mathrm{~mol})$ with stirring at room temperature. After stirring for $1 \mathrm{~h}$, phosphorus oxychloride was removed from the reaction mixture by evaporation. The residue was distilled to give vinylphosphonyl chloride monoethyl ester: bp $71-78^{\circ} \mathrm{C}(17 \mathrm{mmHg})$. To a mixture of $n$-propylamine $(1.5 \mathrm{~g}, 0.025 \mathrm{~mol})$ and triethylamine $(3.0 \mathrm{~g}, 0.03 \mathrm{~mol})$ in $10 \mathrm{ml}$ of diethyl ether was added dropwise vinylphosphonyl chloride monoethyl ester $(3.9 \mathrm{~g}$, $0.025 \mathrm{~mol}$ ) with stirring at $-15^{\circ} \mathrm{C}$. After stirring for $15 \mathrm{~min}$, the precipitate triethylamine hydrochloride was removed by filtration. The filtrate was evaporated and the residue was distilled to give $3.1 \mathrm{~g}$ of $\mathbf{1}(71 \%$ yield $)$ : bp 95- $100^{\circ} \mathrm{C}(0.8 \mathrm{mmHg}) ;{ }^{1} \mathrm{H}$ NMR $\left(\mathrm{CDCl}_{3}\right)$ $\delta 0.92\left(\mathrm{t}, J=7.0 \mathrm{~Hz}, \mathrm{CH}_{2} \mathrm{CH}_{2} \mathrm{C}_{3}, 3 \mathrm{H}\right), 1.32$ (m, $\mathrm{CCH}_{2} \mathrm{C}$ and $\left.\mathrm{OCH}_{2} \mathrm{CH}_{3}, 5 \mathrm{H}\right), 2.90(\mathrm{~m}$, $\mathrm{NCH}_{2} \mathrm{C}$ and $\left.\mathrm{NH}, 3 \mathrm{H}\right), 4.07\left(\mathrm{~m}, \mathrm{OCH}_{2} \mathrm{C}, 2 \mathrm{H}\right)$, $5.4-6.4 \mathrm{ppm}\left(\mathrm{m}, \mathrm{CH}_{2}=\mathrm{CHP}, 3 \mathrm{H}\right) ;{ }^{31} \mathrm{P} \mathrm{NMR}$ $\left(\mathrm{CDCl}_{3}\right) \delta+21.7$.

\section{Copolymerization of $\mathbf{1}$ with $\mathbf{2}$}

A typical run was as follows (entry 6). A mixture of $1(0.177 \mathrm{~g}, 1.0 \mathrm{mmol})$ and $\mathbf{2 b}(0.182 \mathrm{~g}$, $1.0 \mathrm{mmol}$ ) in $0.3 \mathrm{ml}$ of DMF heated under

argon at $130^{\circ} \mathrm{C}$. After $89 \mathrm{~h}$ the mixture was poured into a large amount of a mixture of diethyl ether and $n$-hexane $(50: 50 \mathrm{vol} \%)$ to precipitate the polymeric material. The material was isolated by decantation and dried in vacuo to give $0.21 \mathrm{~g}$ ( $59 \%$ yield) of $\mathbf{3 b}$.

\section{Hydrolysis of Copolymer 3}

To $0.18 \mathrm{~g}$ of the copolymer $\mathbf{3 b}$ (entry 6) in $0.3 \mathrm{ml}$ of acetonitrile, $0.3 \mathrm{ml}$ of $6 \mathrm{~N}$ hydrochloric acid was added at room temperature. The mixture was kept at $150^{\circ} \mathrm{C}$ for $556 \mathrm{~h}$. Then, $5 \mathrm{ml}$ of water was added to the reaction mixture and the solution was poured into a large amount of acetonitrile to precipitate the solid material, followed by decantation to give 4 quantitatively. The supernatant was evaporated to give the mixture of 5 and $6:{ }^{1} \mathrm{H}$ NMR of $4\left(\mathrm{D}_{2} \mathrm{O}\right) \delta 1.5-2.0\left(\mathrm{~m}, \mathrm{CH}_{2} \mathrm{P}, 4 \mathrm{H}\right)$, 7.55 and 7.74 (m, ArP, 5H); IR (neat) $1250 \mathrm{~cm}^{-1}\left(v_{\mathrm{P}=\mathrm{O}}\right) .{ }^{1} \mathrm{H}$ NMR of the mixture of 5 and $6\left(\mathrm{D}_{2} \mathrm{O}\right) \delta 0.96\left(\mathrm{t}, J=7.40 \mathrm{~Hz}, \mathrm{CH}_{3} \mathrm{C}\right.$, $3 \mathrm{H}), 1.68\left(\mathrm{~m}, \mathrm{CC}_{2} \mathrm{CH}_{2} \mathrm{~N}, 2 \mathrm{H}\right), 1.80(\mathrm{~m}$, $\left.\mathrm{OCH}_{2} \mathrm{CH}_{2} \mathrm{CH}_{2} \mathrm{O}, 2 \mathrm{H}\right), 2.95(\mathrm{t}, J=6.94 \mathrm{~Hz}$, $\left.\mathrm{CCH}_{2} \mathrm{~N}, 2 \mathrm{H}\right), 3.67 \mathrm{ppm}\left(\mathrm{t}, J=6.33 \mathrm{~Hz}, \mathrm{CCH}_{2} \mathrm{O}\right.$, $4 \mathrm{H})$.

\section{Determination of Monomer Reactivity Ratios}

A general procedure is given as follows. Monomers $\mathbf{1}$ and $\mathbf{2 b}$ of various feed ratios $([\mathbf{1}]+[2 \mathrm{~b}]=1.0 \mathrm{mmol})$ were placed in $0.15 \mathrm{ml}$ of $\mathrm{PhCN}$ under argon and kept at $130^{\circ} \mathrm{C}$ in a sealed tube. After $12 \mathrm{~h}$, the reaction mixture was poured into a large amount of a diethyl ether- $n$-hexane $(50: 50 \mathrm{vol} \%)$ mixed solvent to precipitate the copolymer. The copolymer composition was determined by ${ }^{1} \mathrm{H}$ NMR spectroscopy. The monomer reactivity ratios were determined by using Mayo-Lewis meth- 
Hydrogen-Transfer Alternating Copolymerization

Table I. Copolymerization of $P$-ethenyl- $N$ - $n$-propylphosphonamidic acid ethyl ester (1) with cyclic phosphonites $2^{\mathrm{a}}$

\begin{tabular}{|c|c|c|c|c|c|c|}
\hline Entry & $\begin{array}{c}\text { Cyclic } \\
\text { phosphonite } 2\end{array}$ & Solvent & $\frac{\text { Temp. }}{{ }^{\circ} \mathrm{C}}$ & $\frac{\text { Time }}{h}$ & $\begin{array}{l}\text { Yield }^{\mathrm{b}} \\
\%\end{array}$ & Mol. wt. ${ }^{d}$ \\
\hline 1 & $2 a$ & $\mathrm{CD}_{3} \mathrm{CN}$ & 130 & 242 & 56 & 900 \\
\hline 2 & $2 a$ & PhCN & 130 & 176 & 56 & 890 \\
\hline 3 & $2 b$ & $\mathrm{CD}_{3} \mathrm{CN}$ & 130 & 214 & 52 & 990 \\
\hline 4 & $2 \mathbf{b}$ & $\mathrm{PhCN}$ & 130 & 70 & 56 & 940 \\
\hline 5 & $2 \mathbf{b}$ & $\mathrm{PhCN}$ & 150 & 70 & 62 & 1100 \\
\hline 6 & $2 b$ & DMF & 130 & 89 & 59 & 1300 \\
\hline 7 & $2 c$ & $\mathrm{CD}_{3} \mathrm{CN}$ & 130 & 102 & $31^{\mathrm{c}}$ & 930 \\
\hline 8 & $2 c$ & $\mathrm{PhCN}$ & 130 & 53 & $19^{c}$ & 760 \\
\hline
\end{tabular}

a Copolymerization was carried out in the equimolar feed ratio of $\mathbf{1}$ and $\mathbf{2}$.

b Diethyl ether- $n$-hexane $(50: 50 \mathrm{vol} \%)$, insoluble part.

c Diethyl ether, insoluble part.

d Determined by GPC with polystyrene standard.

od. $^{8}$

\section{Measurements}

${ }^{1} \mathrm{H}$ and ${ }^{31} \mathrm{P}$ NMR spectra were recorded on a $250 \mathrm{MHz}$ Bruker AC250T NMR spectrometer and $36.4 \mathrm{MHz}$ JEOL FX-90Q NMR spectrometer, respectively. IR spectra were recorded on a Shimadzu IR-27G spectrometer. Gel permeation chromatographic (GPC) and high pressure liquid chromatographic (HPLC) analyses were performed by using a Hitachi 655A apparatus with UV and RI detectors under the following condition: GPC analysis, Gelpack GL-A130 and A120 columns with chloroform eluent at a flow rate of $1.0 \mathrm{ml}$ $\min ^{-1}$; HPLC analysis, Gelpack GL-W520 column with water eluent at a flow rate of $1.0 \mathrm{ml} \mathrm{min}^{-1}$.

\section{RESULTS AND DISCUSSION}

Alternating Copolymerization of 1 with Cyclic

\section{Phosphonites 2}

Copolymerizations of 1 with three monomers of cyclic phosphonites 2 were carried out without any added catalyst to produce the respective alternating copolymers $3 \mathbf{a}-\mathbf{c}$ (Table I). Three solvents, acetonitrile, benzonitrile, and DMF, were used for the copolymerization. In all cases the copolymerization occurred, but the molecular weight of the copolymers was not high. In our previous results on copolymerization of vinylphosphonic acid monoethyl ester with cyclic phosphonites, the molecular weight of the resulting copolymer was relatively high. This difference is probably due to the reactivity difference of the anionic site of zwitterion species: the phosphonate anion was more reactive than the phosphonamide anion. A similar tendency has been reported in the copolymerization of cyclic phosphonites with acrylic acid and with acrylamide. ${ }^{2}$ In the present copolymerization, the conversion of the monomers $\mathbf{1}$ and $\mathbf{2}$ was quantitative; the yield of $\mathbf{3}$, however, was not high. This is probably because the lower molecular weight portion was lost with dissolving in a non-solvent during the work-up procedure.

The structure of the alternating copolymers was confirmed by ${ }^{1} \mathrm{H}$ and ${ }^{31} \mathrm{P}$ NMR spectroscopy. Figure 1 shows the ${ }^{1} \mathrm{H}$ NMR spectrum of the copolymer $\mathbf{3 b}$ (in $\mathrm{CDCl}_{3}$ ) (entry 6 in Table I). Peaks' assignment is as follows: triplet-like peak a at $\delta 0.91 \mathrm{ppm}$ due to methyl protons of $n$-propyl group, triplet-like peak b centered at $\delta 1.29 \mathrm{ppm}$ due to methyl protons 


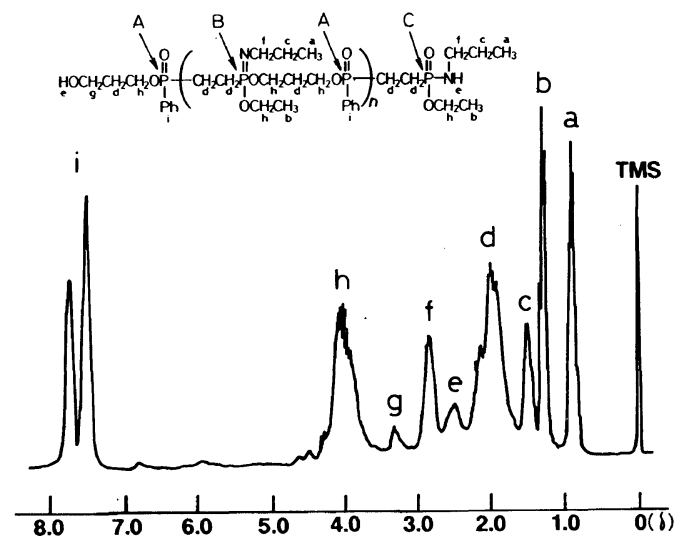

Figure 1. $250 \mathrm{MHz}^{1} \mathrm{H}$ NMR spectrum of copolymer $\mathbf{3 b}$ (entry 6) in $\mathrm{CDCl}_{3}$.

of ethyl group, broad peak c at $\delta 1.48 \mathrm{ppm}$ due to methylene protons of $\mathrm{NCH}_{2} \mathrm{CH}_{2} \mathrm{CH}_{3}$, multiplet peak d at $\delta 1.99 \mathrm{ppm}$ due to methylene protons of $\mathrm{OCH}_{2} \mathrm{CH}_{2} \mathrm{CH}_{2} \mathrm{O}$ and $\mathrm{PC}_{2}{ }_{2} \underline{\mathrm{C}}_{2} \mathrm{P}$, broad peak e at $\delta 2.47 \mathrm{ppm}$ due to the terminal amide proton of $\mathrm{P}(=\mathrm{O}) \mathrm{NH}$ and hydroxyl proton of $\mathrm{CH}_{2} \mathrm{OH}$, broad peak $\mathrm{f}$ at $\delta 2.82 \mathrm{ppm}$ due to methylene protons of $\mathrm{NCH}_{2} \mathrm{C}$, broad peak $\mathrm{g}$ at $\delta 3.30 \mathrm{ppm}$ due to the terminal methylene protons of $\mathrm{CC}_{2} \mathrm{OH}$, multiplet peak h centered at $\delta 4.05 \mathrm{ppm}$ due to methylene protons of $\mathrm{OCH}_{2} \mathrm{C}$, and multiplet peak $\mathrm{i}$ at $\delta 7.50$ and $7.75 \mathrm{ppm}$ due to phenyl protons of $\mathrm{PPh}$. The peak e disappeared in measuring in $\mathrm{D}_{2} \mathrm{O}$. From the areas of the respective peaks, the molar ratio in copolymer 3b was found to be $1: 1$. The molecular weight, calculated from the integrated area of the peak $\mathrm{g}$ and the peak $\mathrm{i}$, was 1560 , which agreed well with that obtained by gel permeation chromatographic (GPC) analysis. ${ }^{31} \mathrm{P}$ NMR spectrum of copolymer in $\mathrm{CDCl}_{3}$ showed main two peaks at +44.5 and $+32.1 \mathrm{ppm}$ (relative to $\mathrm{H}_{3} \mathrm{PO}_{4}$ external standard), which were ascribed to two kinds of phosphorus atoms $\mathrm{A}$ and $\mathrm{B}$ as indicated in Figure 1. A small peak at $+33.9 \mathrm{ppm}$ was assigned to the terminal phosphorus atom $\mathrm{C}$ derived from monomer $\mathbf{1}$. The equimolar ratio of two monomers 1 and 2 was also confirmed from the ratio of integrated area of signals $\mathrm{A}$ and $(\mathrm{B}+\mathrm{C})$.

In order to confirm further the structure of copolymer $\mathbf{3}$, the hydrolysis of copolymer $\mathbf{3 b}$ was carried out. 3b in acetonitrile was treated with $6 N$ hydrochloric acid at $150^{\circ} \mathrm{C}$ for $556 \mathrm{~h}$. An acid hydrolysis of $\mathbf{3 b}$ is expected to give $\mathbf{4}$, trimethylene glycol 5, $n$-propylamine hydrochloride 6, and ethyl alcohol 7.

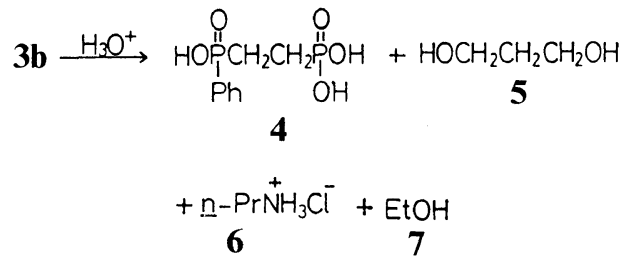

The hydrolysis products $4-7$ were analyzed by high pressure liquid chromatography (HPLC) of the reaction mixture and of the corresponding authentic samples. Furthermore, 4 was isolated by the separation of an acetonitrile-insoluble part from the reaction mixture and confirmed to be 4 by ${ }^{1} \mathrm{H}$ NMR and IR analyses. ${ }^{4}$ The acetonitrile-soluble part was analyzed by ${ }^{1} \mathrm{H}$ NMR to identify the mixture of 5 and 6.

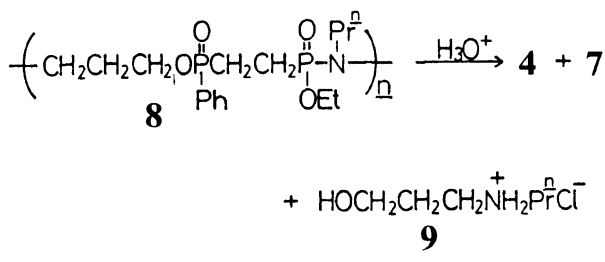

As a possible alternative of $\mathbf{3 b}$, copolymer structure 8 is conceivable. An acid hydrolysis of 8 is expected to give 4, 7, and 9. No detection of 9 by HPLC analysis of the reaction mixture, however, is taken to exclude the possibility of structure 8.

Apparent monomer reactivity ratios between $\mathbf{1}$ and $\mathbf{2 b}$ were determined. Copolymerization experiments were carried out in benzonitrile at $130^{\circ} \mathrm{C}$ for $12 \mathrm{~h}$, which resulted in a low conversion. The copolymer $\mathbf{3 b}$ was isolated and the copolymer composition was determined by ${ }^{31} \mathrm{P}$ NMR analysis. Figure 2 indicates a copolymer composition curve with varying 


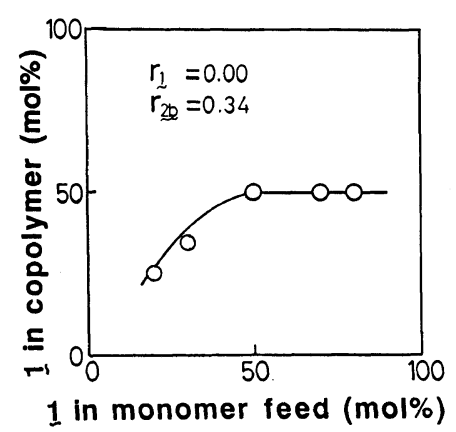

Figure 2. Copolymerization of $\mathbf{1}$ with $2 \mathbf{b}$ at $130^{\circ} \mathrm{C}$ in $\mathrm{PhCN}$ for $12 \mathrm{~h}$. Polymer compositions at various comonomer feeds: $[\mathbf{1}]+[\mathbf{2 b}]=1 \mathrm{mmol}$ in $0.15 \mathrm{ml}$ of $\mathrm{PhCN}$.

monomer feed ratio. The monomer reactivity ratios are thus obtained as $r_{1}=0.00 \pm 0.03$ and $r_{2 b}=0.34 \pm 0.08 .^{8}$

\section{Copolymerization Mechanism}

On the basis of the above data, the following mechanism may be proposed. The first step is the formation of zwitterion $\mathbf{1 0}$ by the Michael-type addition of $\mathbf{1}$ with $\mathbf{2}$ followed by a hydrogen-transfer to give a genetic zwitterion 11. Then, the reaction between two molecules of the genetic zwitterions occurs, where the phosphonium ring of one molecule $\mathbf{1 1}$ is opened by a nucleophilic attack of the anion of the other molecule according to the mode of the Arbuzov reaction. In this process oxidation of phosphorus atom of $\mathbf{2}$ and reduction of carbon atom of $\mathbf{1}$ take place. The propagation proceeds via the successive attack of the genetic zwitterion $\mathbf{1 1}$ onto dimeric zwitterion $12(p=1)$ to lead to a macrozwitterion of an alternating copolymer $\mathbf{3}$. The terminal groups of the isolated copolymer are of phosphonamidic acid monoethyl ester and alcohol structures as shown in Figure 1. These groups were probably formed by the hydrolysis of anion and cation sites of macrozwitterions during the isolation process.

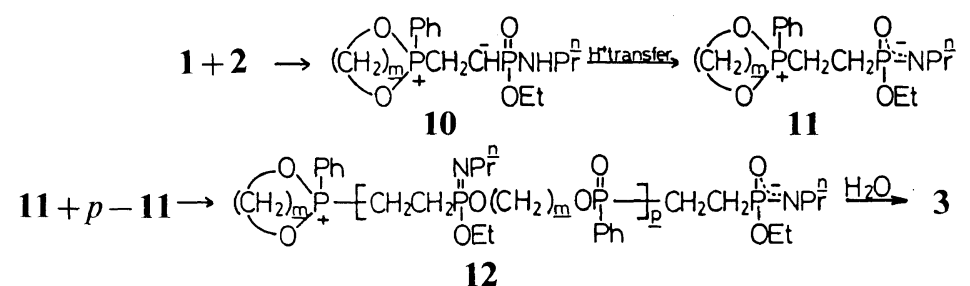

The ${ }^{31} \mathrm{P}$ NMR spectrum (in dimethylformamide- $\left.d^{7}\left(\mathrm{DMF}-\mathrm{d}^{7}\right)\right)$ of the reaction mixture of copolymerization in situ showed signals at +60.9 and +25.5 ppm besides main two peaks. These peaks are ascribed to the phosphorus atoms of the terminal phosphonium ion and ambident anion of $\mathbf{1 1}$ and/or 12, respectively.

In the copolymerization of $\mathbf{1}$ with $\mathbf{2}$, the anions in $\mathbf{1 1}$ and $\mathbf{1 2}$ are of an ambident nature

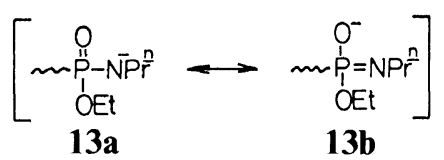

having an anionic site at nitrogen 13a and at oxygen 13b. The copolymerization took place exclusively through $13 \mathbf{b}$ to give $\mathbf{3}$ in a regiospecific manner. This should be compared with the copolymerization of $\mathbf{2 a}$ with acrylamide $^{2}$ and with ethylenesulfonamide. ${ }^{3}$ In these copolymerizations zwitterions having an

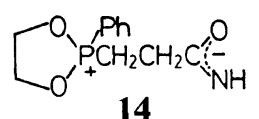<smiles>NS(=O)(=O)NCc1ccccc1</smiles>

ambident anion site $\mathbf{1 4}$ and $\mathbf{1 5}$ are considered. In the ambident anion site, nitrogen atom reacted in $\mathbf{1 4}$ whereas oxygen atom reacted in 15 regioselectively.

Acknowledgment. This work was partly supported by Grants-in-Aid for Scientific 
Research on Priority Area of "New Functionality Materials-Design, Preparation, and Control" (No. 01604004 and 02205010) from the Ministry of Education, Science, and Culture of Japan.

\section{REFERENCES}

1. S. Kobayashi and T. Saegusa, "Alternating Copolymers," T. M. G. Cowie, Ed., Plenum Publishing Co., New York, N. Y., 1985, pp 189-238.

2. T. Saegusa, Y. Kimura, N. Ishikawa, and S.
Kobayashi, Macromolecules, 9, 724 (1976).

3. T. Saegusa, S. Kobayashi, and J. Furukawa, Macromolecules, 11, 1027 (1978).

4. S. Kobayashi, J. Kadokawa, I. F. Yen, and S. Shoda, Macromolecules, 22, 4390 (1989).

5. S. Kobayashi, S. Iwata, M. Abe, and S. Shoda, $J$. Am. Chem. Soc., 112, 1625 (1990).

6. T. Mukaiyama, T. Fujisawa, Y. Tamura, and Y. Yokota, J. Org. Chem., 29, 2572 (1964).

7. S. Kobayashi, M. Tokunoh, and T. Saegusa, Macromolecules, 19, 466 (1986).

8. F. R. Mayo and F. M. Lewis, J. Am. Chem. Soc., 66, 1594 (1944). 